\title{
Highly Efficient Single-step Pretreatment to Remove Lignin and Hemicellulose from Softwood
}

\author{
Irma Bernal-Lugo, ${ }^{\mathrm{a}, *}$ Carmen Jacinto-Hernandez, ${ }^{\mathrm{b}}$ Miquel Gimeno, ${ }^{\mathrm{c}}$ \\ C. Carmina Montiel, ${ }^{\mathrm{c}}$ Fausto Rivero-Cruz, ${ }^{\mathrm{d}}$ and Oscar Velasco ${ }^{\mathrm{e}}$
}

\begin{abstract}
The use of lignocellulosic softwood residues as feedstock for the production of bioethanol and other value-added chemical products has been limited by its high recalcitrance. Alkaline or organosolvent pretreatments have been used to remove recalcitrance in softwoods. Although these methods partially remove lignin and hemicellulose, they also result in low glucose recovery. In the first case, there is low cellulose hydrolizability, and in the second, there is a loss of cellulose. This study evaluated both methods combined into one step: alkaline hydrolysis of the biomass in the presence of an organosolvent. Different conditions of temperature and residence times were assayed. The efficiency of these conditions was quantified as the percentage of lignin and hemicellulose removed from the biomass without loss of cellulose. The substrate produced with the most efficient conditions removed $91 \%$ of the lignin and $89.1 \%$ of the hemicellulose with no loss of cellulose. Enzymatic hydrolysis of this biomass was $90 \%$ to $95 \%$, with a substrate concentration of $3 \%$ and with five filter paper units per gram of cellulose (FPU/g cellulose). These results indicated that this one-step alkaline-organsolvent process, applied as a pretreatment to softwood, allows highly efficient lignin and hemicellulose removal. $100 \%$ of cellulose was recovered, and there was between 90 and $95 \%$ glucose yield after enzymatic digestion.
\end{abstract}

Keywords: Lignocellulosic softwood residues; Recalcitrance; Alkali-organsolvent pretreatment

Contact information: a: Departamento de Bioquimica, Facultad de Quimica, UNAM. Ciudad Universitaria, 04510, Mexico; b: CEVAMEX-INIFAP, Apdo. 10-56250. Texcoco, Mex., Mexico. c: Departamento de Alimentos y Biotecnología, Facultad de Química, UNAM. Ciudad Universitaria, 04510, Mexico; d: Departamento de Farmacia, Facultad de Quimica, UNAM Ciudad Universitaria, 04510, Mexico; e: CIIDIR-IPN, Unidad Durango. Sigma S/N, Frac. 20 de Noviembre II, Dgo, Dgo. 34220, Mexico; *Corresponding author: irmofel@unam.mx

\section{INTRODUCTION}

Environmental pollution and climate change generated by the use of conventional fuels, such as oil, coal, and natural gas foster academic, industrial, and political interest in the use of lignocellulosic residues for the generation of biofuels. Among them, bioethanol production stands out. The advantages of using lignocellulosic residues for the production of bioethanol throughout biotechnological processes lie in protection of the environment by reducing the emission of greenhouse gases, in addition to conserving renewable and non-renewable resources.

The main components of lignocellulosic biomass are cellulose (40 to 60\% of the total dry weight), hemicelluloses (20 to 40\%), and lignin (10 to 25\%) as structural components of the plant cell wall (Sánchez 2009). Cellulose consists of long chains of $\beta$ glucose monomers gathered into microfibril bundles. The hemicelluloses, which are predominantly xylans or glucomanans, are linked to the microfibrils by hydrogen bonds. 
Lignin is a hydrophobic heterogeneous and highly crosslinked phenolic polymer, intimately associated with the polysaccharides (Cosgrove and Jarvis 2012). The lignin component acts as a physical barrier, and its removal allows the hydrolysis and fermentation of the carbohydrates to produce bio-ethanol or to other bio-chemical products.

The processes to convert the lignocellulosic biomass to fermentable sugars consist of two steps: A pre-treatment, in which the cellulose polymers become accessible for their subsequent hydrolysis; followed by an enzymatic hydrolysis of cellulose for its conversion into fermentable sugars. The purpose of the pretreatment is to break down the association between cellulose, hemicellulose, and lignin, besides of disrupting the crystalline structure and reduce the degree of polymerization of the polysaccharides (Chang and Holtzapple 2000, Himmel et al. 2007). However, there is a great variety in the chemical composition of lignocellulosic biomass. For instance, the agroindustrial biomass residues, byproducts of agriculture or its related industry, include cotton stalks, wheat and rice straw, coconut shells, maize cobs, jute sticks, and rice husks. The lignin content in these materials range from 10 to $18 \%$, whereas the content of this hydrophobic compound in forest residues, wood chips, sawdust, and bark, is about 20 to $40 \%$. Because these differences, the type of bound strength established among carbohydrates and with lignin result in structural differences among the various lignocellulosic residues. Additionally, the properties of the monomer precursors are different for each type of lignin; thereby they exhibit different characteristics (Chang and Holtzapple 2000). In regard to this structural heterogeneity, efforts have been made to address the optimization of the pretreatment processes for each lignocellulosic material. These include hydrothermal, diluted acid, ammonia fiber expansion (AFEX), soaking in aqueous ammonia, steam explosion, organic solvents, alkaline solutions, and others (Brodeur et al. 2011; Maurya et al. 2015). Some pretreatments efficiently reduce the recalcitrance, i.e. the natural resistance of lignocellulosic biomass to enzymatic hydrolysis (Himmel et al. 2007), of the most abundant agricultural and hardwood residues, making it possible to attain up to $95 \%$ glucose yields. Some examples are wheat straw pretreated with steam explosion (Talebnia et al. 2010), barley straw pretreated by alkaline-peroxide (Saha and Cota 2010), rice straw with diluted acid (Lau and Dale 2009), and corn stover with AFEX pretreatments (Binod et al. 2010). The same pre-treatments have been successfully applied to residues from hardwood such as poplar (Yan et al. 2014), birch (Mirahmadi et al. 2010), elm beech (Nitsos et al. 2013), and willow (Eklund et al. 1995), and all of these treatments have similar glucose yields. However, the application of these pre-treatments to softwood residues is challenging due to low efficiency of enzymatic hydrolysis (Yu et al. 2011). This is ascribed to the differences in chemical composition and structure of the residues (Ramos et al. 1992). Lignin from agricultural residues contains coumaryl (H), coniferyl (G), and sinapyl (S) alcohols but the predominant precursor of softwood lignin is G. Noteworthy, hardwood lignin also contains $\mathrm{S}$ units in addition to $\mathrm{G}$.

The steam explosion process, with or without $\mathrm{SO}_{2}$ as catalyst, has been extensively studied as a pretreatment method for the bioconversion of several softwoods at temperatures of $160{ }^{\circ} \mathrm{C}$ to $200{ }^{\circ} \mathrm{C}$ in short process times ( $1 \mathrm{~min}$ to $10 \mathrm{~min}$ ). Nonetheless, the substrate exhibited a high content of lignin condensed on the surface of the biomass under this condition, thus limiting the access of the hydrolytic enzymes to the cellulose. According to that, the glucose recovery was between $45 \%$ and $50 \%$ (Wu et al. 1999; Boussaid et al. 2000; Mabee et al. 2006; Ewanick et al. 2007; Monovari et al. 2009). Additionally, at temperatures higher than $200{ }^{\circ} \mathrm{C}$, some cellulose is lost (Stenberg et al. 2000; Ewanick et al. 2007; Yu et al. 2011), and glucose recovery is low. 
To remove the condensed lignin, the pretreated softwood solid residues are subsequently treated with sodium chlorite (Yu et al. 2011) or alkali-oxygen to complete the delignification of the solid substrate (Pan et al. 2004, 2005; Kumar et al. 2011). These softwood lignocellulose substrates obtained after the two sequential processes are then hydrolyzed efficiently by cellulases with $20 \mathrm{FPU} / \mathrm{g}$ cellulose (Pan et al. 2004; Yu et al. 2011). However, when the oxidative delignification treatment is not applied, the required cellulase ranged between 20 and 50 FPU/g cellulose (Pan et al. 2004). Although, the previous treatments produced a substrate with improved enzymatic digestion, the pre- and post-treatment of lignocellulosic residues have disadvantages. The entire delignification treatment with alkali-oxygen requires $3 \mathrm{~h}$ at $100{ }^{\circ} \mathrm{C}$ (Pan et al. 2004) or $2 \mathrm{~h}$ at $80{ }^{\circ} \mathrm{C}$ with sodium chlorite, thereby increasing energy consumption (Yu et al. 2011). Moreover, delignification with sodium chlorite releases toxic gases into the environment (Condie 1986).

Two other protocols reported for softwoods with poor results are alkali and organosolvent pretreatments. The spruce treated with alkali produces a saccharification yield (\% of available glucose) of up to $60 \%$ (Zhao et al. 2008; Mirahmadi et al. 2010). The use of the organosolvent process with $\mathrm{H}_{2} \mathrm{SO}_{4}$ as a catalyst, to pretreat lodgepole pine, loblolly pine, and spruce, yielded $100 \%$ of saccharification efficiency. However, $33 \%$ of the cellulose is lost (Pan et al. 2008; Sannigrahi et al. 2010; Løhre et al. 2017). Thus, there are two main drawbacks in improving the saccharification yield of softwood lignocellulosic residues obtained by the above strategies. First, pretreatment conditions used to modify the lignin structure allow for re-condensation on top of the biomass and causes cellulose losses. Secondly, to attain a saccharification yield above $60 \%$, both a pretreatment to modify lignin structure and an oxidative treatment to remove re-condensed lignin are needed. This study successfully achieves a one-step method for the lignin modification as well as solubilization of lignin and hemicelluloses to increase the saccharification yield of softwood biomass while preventing the loss of cellulose.

\section{EXPERIMENTAL}

\section{Material}

Pinus spp. sawdust was obtained from Durango, Mexico. The species is in the softwood category. Samples consisted of sawdust sifted through a 20-mesh screen and retained in a 40-mesh screen. The moisture content was determined according to Sluiter $e t$ al. (2012).

\section{Methods}

\section{Removal of extractive substances}

Extractive substances were solubilized with acetone from air-dried samples in a Soxhlet extractor for $6 \mathrm{~h}$. The heating rate was adjusted to six changes of solvent per hour in the Soxhlet cartridge (Scan-CM 49:03 2012). The acetone was then drained and the solids were oven dried at $60{ }^{\circ} \mathrm{C}$ to constant weight.

\section{Chemical composition of pre-treated and non-treated sawdust}

Extractive-free sawdust samples were used to determine the content of sugars and lignin by acid hydrolysis using a standard method (Sluiter et al. 2012). Extractive-free material was used to prevent interference of lignin quantification. Soluble lignin was 
estimated in the acid hydrolysate and insoluble lignin as dry water-washed precipitate. Sugars were quantified by high performance liquid chromatography (HPLC) after neutralizing the acid hydrolysate with $20 \%$ sodium carbonate. The HPLC system was equipped with a high performance carbohydrate column (Waters, Co. Milford, MA, USA) and with an RI detector (Waters 2414). The column and the detector were set to a temperature of $30^{\circ} \mathrm{C}$, with a mobile phase of acetonitrile water (85:15) and a flow rate of $1 \mathrm{~mL} / \mathrm{min}$. In each case, the content of glucose, galactose, and mannose co-eluted in the column, and the mannose plus galactose were calculated as the difference between the total hexoses quantified by the HPLC minus the amount of glucose determined with an enzymatic method (Glucose LQ, SPINREACT, Girona, Spain). Structural carbohydrates were calculated from the monosaccharide composition using the stoichiometric hydrolysis factors 0.88 and 0.90 , for sugars with five and six carbons, respectively. The content galactoglucomannan was calculated using the chemical composition (1:1:4) for this softwood polysaccharide (Sjöström 1993). The results were analyzed using pretreatments as the independent variable in the general linear model (GLM) of a one-way ANOVA. The statements of significance were based on a 0.01 probability level. The statistical software used was SAS 9.2 (SAS Institute Inc. Cary, NC, USA).

Lignin present in the pretreatment filtrate was precipitated with sulfuric acid, washed with water, dried, and weighed (Sluiter et al. 2012). Acid-soluble lignin was analyzed by UV spectrometry at $205 \mathrm{~nm}$, and dissolved sugars were estimated as total reducing sugars (Miller 1959) after removing soluble lignin with PVPP.

\section{Pretreatment}

A solution of $3 \%$ sodium hydroxide in $45 \%$ ethanol $(40 \mathrm{~mL})$ and $5 \mathrm{~g}$ of extractivefree sawdust were placed in a 316 stainless steel $100 \mathrm{~mL}$ homemade reactor, which was heated with a ceramic jacket. The operating temperature was monitored with two independent thermocouples: one to measure the temperature in the heating jacket and the other to measure temperature inside the reactor. In this system, the effect of temperature and residence time on the improvement of enzymatic hydrolysis of the sawdust was evaluated by varying the conditions of temperature and residence time (Table 1).

After completing the heating time, the reactor was decompressed rapidly and cooled. The suspension was vacuum-filtered. The water-insoluble solids were washed until a $\mathrm{pH}$ of 5.0 was reached and were then stored at $4{ }^{\circ} \mathrm{C}$. Rainwater was used to wash the water insoluble solids.

Table 1. Pretreatment Conditions*

\begin{tabular}{|c|c|c|c|}
\hline Temperature $\left({ }^{\circ} \mathrm{C}\right)$ & Pressure (Bar) & Time $(\mathrm{min})$ & Pretreatment Condition \\
\hline 150 & 5 & 30 & $\mathrm{~A}$ \\
\hline 160 & 10 & 120 & $\mathrm{~B}$ \\
\hline 165 & 10 & 120 & $\mathrm{C}$ \\
\hline${ }^{*}(3 \%) \mathrm{NaOH}$ in $45 \%$ ethanol
\end{tabular}

\section{Enzymatic hydrolysis}

Enzymatic hydrolysis was conducted at $50{ }^{\circ} \mathrm{C}$ and $150 \mathrm{rpm}$ with a $3 \%$ substrate concentration in a citrate buffer $(50 \mathrm{mM}, \mathrm{pH} 4.8)$, which contained $0.01 \%$ sodium azide to inhibit microbial growth. The supernatant of the reaction mixture was sampled $(0.5 \mathrm{~mL})$ after 12, 24, 48, 72, and $96 \mathrm{~h}$. Each sample was stored at $-20^{\circ} \mathrm{C}$ before glucose analysis. 
The cocktail of cellulase enzymes included Accelerase 1500, Accelerase XY, and Accelerase BG (Genencor, Rochester, NY, USA). FPU activities were determined as described previously (Ghose 1987). The $\beta$-glucosidase activity in the Accelerase BG was measured using para-nitrophenyl- $\beta$-D-glucopyranoside (pNPG) as a substrate (Wood and Bhat 1988), and the activity of xylanase was determined using birchwood-xylan as a substrate. The enzymatic cocktail was a mixture of cellulase, xylanase, and $\beta$-glucosidase with an activity ratio of 1:20:64.

The glucose yield was determined as the glucose produced by enzymatic hydrolysis expressed as a percentage of the maximum glucose content. The glucose produced by enzymatic hydrolysis was calculated by subtracting the glucose present in the mixture of enzymes from the total glucose quantified in each sample.

\section{RESULTS AND DISCUSSION}

\section{Initial Chemical Composition of Pine Sawdust Free of Extractives}

The total lignin content of pine sawdust free of extractives was $30.1 \%$, while hexoses (glucose, galactose, mannose) were $66.5 \%$, and pentoses (xylose and arabinose) accounted for $3.17 \%$ (see Table 3, fresh biomass). Because of the high sugar concentration, this biomass is an appropriate substrate for fermentation. The chemical composition was within the range for softwood in previous reports (Söderström et al. 2002; Monavari et al. 2009).

\section{Recovery of Biomass after Pretreatment and Content of Lignin and Hemicelluloses}

Lignin and sugar solubilization were associated with the severity of the pretreatment. The pretreatments applied to pine sawdust (Table 1) produced dark brown liquor and an insoluble light brown material. The quantities of lignin and sugars dissolved in the dark brown liquor are shown in Table 2.

Table 2. Lignin and Sugars Dissolved in Brown Liquor after Pretreatment of $1 \mathrm{~g}$ of Extractive-free Biomass

\begin{tabular}{|c|c|c|c|}
\hline Pretreatment & A & B & C \\
\hline Sugars $\mathrm{mg} \mathrm{g}^{-1}$ & $46.7 \pm 6.8^{1}(6.7 \%)^{2}$ & $67.3 \pm 1.1 \quad(9.6 \%)$ & $140.3 \pm 3.5(20.1 \%)$ \\
\hline Lignin $\mathrm{mg} \mathrm{g}^{-1}$ & $137.7 \pm 4.0(45.7 \%)$ & $195.6 \pm 2.5(64.9 \%)$ & $237.6 \pm 2.5(78.9 \%)$ \\
\hline Dry biomass (\%) & 18.4 & 26.3 & 37.8 \\
\hline
\end{tabular}

The alkaline-ethanol explosion pretreatments, either B or C, were effective for removing the lignin and some lignocellulosic sugars, although pretreatment $\mathrm{C}\left(165{ }^{\circ} \mathrm{C}\right)$ was better than B because it dissolved $79 \%$ of the lignin and $20 \%$ of the sugars. The mass balance was calculated by adding the percentage of solid yields (Table 3 ) to the lignin and sugars dissolved in the brown liquor (Table 2) after each pretreatment. The mass balance ranged between $92.4 \%$ in pretreatment $A$ and $97.8 \%$ in pretreatment $C$. The lower recovery of biomass after pretreatment $\mathrm{A}$ and $\mathrm{B}$ could be due to one of two possibilities. The temperature conditions of the biomass pretreatment release lignin-sugars complexes (LCC) 
or convert sugars to furfural. However, none of these compounds were identified.

The amount recovered, the color, and the chemical composition of the insoluble solids varied with each pretreatment. The yield of insoluble solids diminished as the severity of the pretreatment increased (Table 3). Similarly, as the severity increased, the lignin content decreased (Table 3), and the brown color of the biomass was lighter. This result indicated that lignin was solubilized, as shown in Table 2, and therefore, it must have been previously modified.

The sugar composition of recovered solids was modified after pretreatment. The content of hemicellulosic sugars diminished from $159.5 \mathrm{mg} \mathrm{g}^{-1}$ to $17.4 \mathrm{mg} \mathrm{g}^{-1}$ dry weight as the pretreatment severity increased. An abundance of glucose $\left(537.4 \mathrm{mg} \mathrm{g}^{-1}\right.$ to $860.6 \mathrm{mg}$ $\mathrm{g}^{-1}$ ) was positively related to the pretreatment conditions.

The amount of sugars in Table 3 was converted to structural carbohydrates as described in the methodology section (Table 4). There were no significant differences in the cellulose content between the control and the pretreated samples (ANOVA, $p=0.05$ ). However, the hemicellulose content diminished with the increased severity of the pretreatment. Although the control had 16\% hemicellulose, pretreatment $\mathrm{C}$ showed $1.1 \%$. The significant loss of C-6 sugars from hemicellulose fraction (Table 3 ) can be recovered, as oligomers or as monomers, from the black liquor (see methods and Table 2). These compounds can be added during cellulose hydrolysis, since most commercial preparations from cellulase contain high amount of hemicelulases activities. In this way the total C-6 sugars obtained from one gram of biomass may increase and therefore, bio-ethanol yields. The mannose and galactose recovered from the black liquor also could be used as substrate for bio-production of cellulase or as chemical building blocks in the synthesis of polyhydroxylated compounds or for producing immuno-stimulatory agents. The final use given to the sugars recovered from black liquor would depend of the balance between the cost of including another step in the process and the profit obtained from the generated product.

Table 3. Solids Yield and Chemical Composition of Pretreated and notPretreated Extractives-free Biomass

\begin{tabular}{|c|c|c|c|c|c|c|}
\hline $\begin{array}{l}\text { Pretreatment } \\
\text { Conditions }\end{array}$ & $\begin{array}{l}\text { Solids } \\
\text { Yield } \\
(\%)^{1}\end{array}$ & $\begin{array}{l}\text { Glucose } \\
\mathrm{mg} \mathrm{g}^{-1}\end{array}$ & $\begin{array}{c}\text { Man+Gal } \\
\mathrm{mg} \mathrm{g}^{-1}\end{array}$ & $\begin{array}{l}\text { Xylose } \\
\mathrm{mg} \mathrm{g}^{-1}\end{array}$ & $\begin{array}{l}\text { Arabinose } \\
\mathrm{mg} \mathrm{g}^{-1}\end{array}$ & $\begin{array}{l}\text { Lignin }^{4} \\
\text { mg g- }^{-1}\end{array}$ \\
\hline $\begin{array}{c}\text { Fresh } \\
\text { Biomass }\end{array}$ & 100 & $537.4(11.7)^{2}$ & $127.8(10.2)$ & $18.5(0.9)$ & $13.2(1.0)$ & $301.0(28.4)$ \\
\hline $\mathrm{A}$ & 74 & $664.8(41.3)$ & $107.4(8.6)$ & $14.8(1.3)$ & $8.5(2.4)$ & $204.1(16.6)$ \\
\hline$B$ & 69 & $770.5(99.1)$ & $83.7(10.0)$ & $6.1(0.5)$ & $\mathrm{ND}^{3}$ & $128.0(11.7)$ \\
\hline C & 60 & $860.6(96.0)$ & $12.4(1.9)$ & $5.0(3.4)$ & ND & $85.5(19.5)$ \\
\hline
\end{tabular}

Table 4. Content of Structural Carbohydrates and Lignin in Biomass Recovered from $100 \mathrm{~g}$ of Extractives-free, Pretreated Pine Sawdust

\begin{tabular}{|c|c|c|c|}
\hline Pretreatment Conditions & Cellulose $(\%)$ & Hemicellulose* $\left.^{*} \%\right)$ & Lignin (\%) \\
\hline CONTROL & 46.06 & 16.0 & 30.1 \\
\hline A & 42.8 & 9.8 & 16.1 \\
\hline B & 44.61 & 8.1 & 8.8 \\
\hline C & 46.3 & 1.1 & 5.1 \\
\hline
\end{tabular}


The biomass generated by pretreatments B and C exhibited lignin contents of $12.8 \%$ and $8.5 \%$, respectively. In pretreated biomass containing less than $15 \%$ of lignin the enzymatic hydrolysis of cellulose has been shown to be highly efficient (Yu et al. 2011). This result suggests that biomass obtained with pretreatments $\mathrm{B}$ and $\mathrm{C}$ is more susceptible to the action of cellulase than that produced by steam-pretreated biomass with $40 \%$ content (Monavari et al. 2009; Chacha et al. 2011) and similar to that obtained when the steampretreated biomass was delignified (Yu et al. 2011).

\section{Effect of Lignin and Hemicellulose Removal on Saccharification}

The efficiency of enzymatic hydrolysis of pretreated biomass increased as the lignin and hemicellulose content was decreased. The glucose yield of biomass from pretreatments $\mathrm{A}$ and $\mathrm{B}$ was $14.5 \%$ and $53.9 \%$, while pretreatment $\mathrm{C}$ yielded $90 \%$ to $95 \%$ of glucose in $72 \mathrm{~h}$, with an enzymatic load of 5 FPU g ${ }^{-1}$ (Fig. 1).

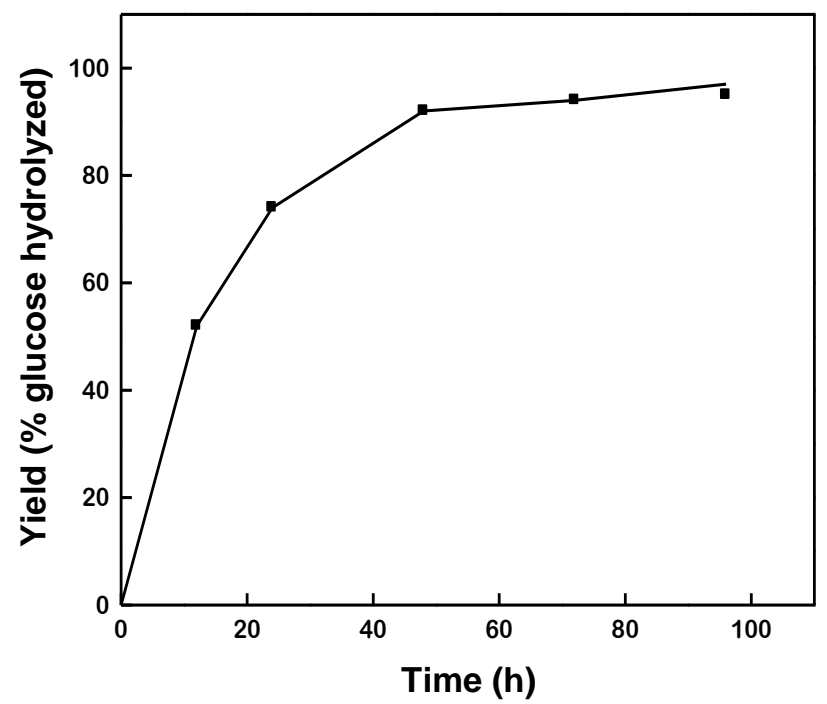

Fig. 1. Five PFU/g of cellulose hydrolyzes $95 \%$ of pretreated substrate in $72 \mathrm{~h}$, under the conditions of pretreatment $\mathrm{C}$, with a solids concentration of $3 \%($

These results indicate that the method of alkali-organosolvent pretreatment is better for improving cellulose saccharification than the acidic-organosolvent pretreatment reported by Pan et al. (2008). This is because the latter resulted in the loss of cellulose (33\%), the lignin removal was less than $50 \%$, and $20 \mathrm{FPU} / \mathrm{g}$ cellulose was used for saccharification; however, the former method resulted in $100 \%$ cellulose recovery $91 \%$ lignin removal and 90 to $95 \%$ saccharification with only 5FPU/g of cellulose.

The efficiency of the pretreatment method here proposed may be a consequence of the induced changes in composition and structure that may affect the lignocellulosic residues during pretreatment, regardless of their origin. These changes impact cellulose structure and improve its enzymatic hydrolysis rate (Chang and Hotzapple 2000). These changes have been reported, and are described in the light of alkali-organosolvent pretreatment in the present study. The high temperature- $\mathrm{NaOH}$ conditions promote the hydrolysis of the ether bonds between guaiacyl units and the ester linkages among ligninpolysaccharides (Kim et al. 2016). The saponification of the last bonds also increases the depolymerization of lignin and hemicelluloses, which increases the material porosity (Yu et al. 2011). An increase in the substrate porosity increases the accessibility of cellulase to 
cellulose during the saccharification step (Grethlein 1985). In addition to the above reactions, the presence of ethanol dissolves the hemicellulosic sugars or its oligosaccharides and the fragmented lignin, avoiding its deposition on the surface of cellulose (Kumar et al. 2012).

The separation of the lignin fragments and hemicelluloses from solids after pretreatment avoids the unspecific binding of cellulase to lignins, an interaction that results in a decrease of saccharification rate (Kumar et al. 2012). The other advantage of this separation is the elimination of fermentation inhibitors such as furfural or hidroxymethylfurfural, which could be formed by dehydration of hemicellulosic sugars (Monavari et al. 2009). Furthermore, the explosive release of the ethanolic -hydroxide pressure allows the disruption of the cellulose structure, increasing the accessibility surface area of the substrate for enzymatic hydrolysis (Mabee et al. 2006).

Lignin obtained from this process exhibited a pure form, making it suitable to be used in other applications, which would increase the value of the extracted lignin (Pan et al. 2008). With this approach, the total cost of lignocellulosic waste and pretreatment would be not only used in ethanol production but also to obtain high quality lignin and cellulose suitable to produce enzymes (cellulose and other hydrolases). The distribution of the process cost would increase the profitability of the process. The lab efficiency of this pretreatment suggests that it could be used at a commercial scale on a biorefinery platform in the future.

Finally, the results show that the pretreatment proposed here allows for the reduction of the recalcitrance of pine sawdust obtaining a high quality lignin and total cellulose recovery.

\section{CONCLUSIONS}

1. The alkaline-organosolvent pretreatment at $165{ }^{\circ} \mathrm{C}$ and $2 \mathrm{~h}$ residence time (pretreatment $\mathrm{C}$ ) was highly efficient in removing lignin and hemicellulose from pine sawdust in a single step with no cellulose loss.

2. The pretreated biomass produced $90 \%$ to $95 \%$ glucose yield using only 5 FPU cellulases.

\section{ACKNOWLEDGMENTS}

Irma Bernal-Lugo is grateful to Facultad de Química, UNAM, for funding this study (Grant $\mathrm{N}^{\circ}$ PAIP/5000/9114) and acknowledges the technical assistance of Q. Laurel Fabila and Dr. Victor Zaldivar Machorro.

\section{REFERENCES CITED}

Binod, P., Sindhu, R., Singhania, R. R., Vikram, S., Devi, L., Nagalakshmi, S., Kurien, N., Sukumaran, R. K., and Pandey, A. (2010). "Bioethanol production from rice straw: An overview," Bioresource Technol. 101(13), 4767-4774. DOI: 10.1016/j.biotech.10.079 
Boussaid, A. L., Esteghlalian, A. R., Gregg, D. J., Lee, K. H., and Saddler, J. N. (2000). "Steam pretreatment of Douglas-fir wood chips. Can conditions for optimum hemicellulose recovery still provide adequate access for efficient enzymatic hydrolysis," Appl. Biochem. Biotechnol. 84-86(1-9), 693-705.

Brodeur, G., Yau, E., Ramachandran, K. B., Badal, K., Collier, J., and Ramakrishnan, S. (2011). "Chemical and physicochemical pretreatment of lignocellulosic biomass," Enzyme Res. 2011 (2011), Article ID 787532. DOI: 10.4061/2011/787532

Chacha, N., Toven, K., Mtui, G., Katima, J., and Mrema, G. (2011). "Steam pretreatment of pine (Pinus patula) wood residue for the production of reducing sugars," Cellulose Chem. Technol. 45(7-8), 495-501.

Chang, V. S., and Holtzapple, M. T. (2000). "Fundamental factors affecting biomass enzymatic reactivity," Appl. Biochem. Biotechnol. 84(1), 5-37. DOI: 10.1385/ABAB:84-86:1-9:5

Condie, L. W. (1986). "Toxicological problems associated with chlorine dioxide," Am. Water Works Assoc J. 78(6), 73-78.

Cosgrove, D. J., and Jarvis, M. C. (2012). "Comparative structure and biomechanics of plant primary and secondary cell walls," Frontiers Plant Sci. 3, 204. DOI: 10.3389/fpls.2012.00204

Eklund, R., Galbe, M., and Zacchi, G. (1995). "The influence of $\mathrm{SO}_{2}$ and $\mathrm{H}_{2} \mathrm{SO}_{4}$ impregnation of willow prior to steam pretreatment," Biores. Eng. 52(3), 225-229. DOI: 10.1016/0960-8524(95)00042

Ewanick, S. M., Bura, R., and Saddler, J. N. (2007). "Acid-catalyzed steam pretreatment of lodgepole pine and subsequent enzymatic hydrolysis and fermentation to ethanol," Biotechnol. Bioeng. 98(4), 737-746. DOI: 10.1002/bit.21436

Ghose, T. K. (1987). "Measurement of cellulose activities," Pure App Chem. 59(2), 257258. DOI: $10.1351 /$ pac198759020257

Grethlein, H. E. (1985). "The effect of pore size distribution on the rate of enzymatic hydrolysis of cellulosic substrates," Nature Biotechnol. 3(2), 155-160.

Himmel, M. E., Nimlos, M. R., Ding, S. Y., Brady, J. W., Johnson, D. K., Foust, T. D., and Adney, W. S. (2007). "Biomass recalcitrance: engineering plants and enzymes for biofuels production," Science 315(5813), 804-807. DOI: 10.1126/science.1137016

Kim, J. S., Lee, Y. Y., and Kim, T. H. (2016). "A review on alkaline pretreatment technology for bioconversion of lignocellulosic biomass," Bioresour. Technol. 199, 42-48. DOI: 10.1016/j.biortech.2015.08.085 0960-8524.

Kumar, L., Chandra, R., and Saddler, J. (2011). "Influence of steam pretreatment severity on post-treatments used to enhance the enzymatic hydrolysis of pretreated softwoods at low enzyme loadings," Biotechnol. Bioeng. 108(10), 2300-2311.

DOI: $10.1002 /$ bit.23185

Lau, M. W., and Dale, B. E. (2009). "Cellulosic ethanol production from AFEX-treated corn stover using Saccharomyces cerevisiae 424A (LNH-ST)," P. Natl. Acad. Sci. USA 106(5), 368-1373. DOI: 10.1073/pnas.0812364106

Løhre, C., Kleinert, M., and Barth, T. (2017). “Organosolv extraction of softwood combined with lignin-to-liquidsolvolysis as a semi-continuous percolation reactor," Biomass Bioenerg. 99, 147-155. DOI: 10.1016/J.Biombioe.2017.02.014

Mabee, W. E., Gregg, D. J., Arato, C., Kendall, E., Berlin, A., Bura, R., Gilkes, N., Mirochnik, O., Pan, X., Pye, E. K., and Saddler, J. N. (2006). "Updates on softwoodto-ethanol process," Devel. Appl. Biochem. Biotechnol. 129(1), 55-70.

DOI: 10.1385/ABAB:129:1:55 
Maurya, D. P., Singla, A., and Negi, S. (2015). "An overview of key pretreatment process for biological conversion of lignocellulosic biomass to bioethanol," Biotech 5(4), 597-609. DOI: 10.1007/s13205-015-0279-4

Mirahmadi, K., Kabir, M. M., Jeihanipour, A., Karimi, K., and Taherzadeh, M. J. (2010). "Alkaline pretreatment of spruce and birch to improve bioethanol and biogas production," BioResources 5(2), 928-938.

Miller, G. L. (1959). "Use of dinitrosalicylic acid reagent for determination of reducing sugar," Anal. Chem. 31(3), 426-428.

Monavari, S., Galbe, M., and Zacchi, G. (2009). "The influence of solid/liquid separation techniques on the sugar yield in two-step dilute acid hydrolysis of softwood followed by enzymatic hydrolysis," Biotechnology for Biofuels 2(6). DOI: 10.1186/1754-68342-6

Nitsos, C. K., Matis, K. A, and Triantafyllidis, K. S. (2013). "Optimization of hydrothermal pretreatment of lignocellulosic biomass in the bioethanol production process," Chem Sus Chem 6(1), 110-122. DOI: 10.1002/cssc.201200546

Pan, X., Xie, D., Gilkes, N., Gregg, D. J., and Saddler, J. N. (2005). "Strategies to enhance the enzymatic hydrolysis of pretreated softwood with high residual lignin content," Appl. Biochem. Biotechnol. 123(1-3),1069-1079.

Pan, X., Zhang, X., Gregg, D. J., and Saddler, J. N. (2004). "Enhanced enzymatic hydrolysis of steam-exploded Douglas fir wood by alkali-oxygen post-treatment," Appl. Biochem Biotechnol. 115(1-3), 1103-1114.

Pan, X., Xie, D., Yu, R. D., and Saddler, J. N. (2008). "The bioconversion of mountain pine beetle-killed lodgepole pine to fuel ethanol using the organosolv process," Biotechnol. Bioeng. 101(1), 39-48. DOI:10.1002/bit.21883

Ramos, L. P., Beruil, C., and Saddler, J. N. (1992). "Comparison of steam pretreatment of eucalyptus, aspen, and spruce wood chips and their enzymatic hydrolysis," Appl. Biochem. Biotech. 34/35(1), 37-48.

Saha, B. C. and Cotta, M. N. (2010). "Comparison of pretreatment strategies for enzymatic saccharification and fermentation of barley straw to ethanol," New Biotechnol. 27(1), 10-16. DOI: 10.1016/j.nbt.2009.10.005

Sánchez, C. (2009). "Lignocellulosic residues: Biodegradation and bioconversion by fungi," Biotechno.l Adv. 27, 185-194. DOI:10.1016/j.biotechadv.2008.11.001

Sannigrahi, P., Miller, S. J., and Ragauskas, A. J. (2010). "Effects of organosolv pretreatment and enzymatic hydrolysis on cellulose structure and crystallinity in Loblolly pine," Carbohyd. Res. 345(7), 965-970. DOI: 10.1016/j.carres.2010.02.010.

Scan-CM 49:03 (2003). "Wood chips for pulp production and pulp. Content of acetonesoluble matter," Scandiniavan Pulp, Paper and Board Testing Committee. Stockholm, Sweden.

Sjöström, E. (1993). "Wood polysaccharides," in: Wood Chemistry: Fundamentals and Applications, Academic Press, San Diego, CA, pp. 51-70.

Sluiter, A., Hames, B., Ruiz, R., Scarlata, C., Sluiter, J., Templeton D., and Crocker D. (2012). Determination of Structural Carbohydrates and Lignin in Biomass. (NREL / TP-510-4628), National Renewable Energy Laboratory, Golden, CO, USA.

Söderström, J., Pilcher, L., Galbe, M., and Zacchi, G. (2002). "Two-step steam pretreatment of softwood with $\mathrm{SO}_{2}$ impregnation for ethanol production, "Appl. Biochem. Biotechnol. 98-100(1-9), 5-21.

Stenberg, K., Bollók, M., Réczey, K., Galbe, M., and Zacchi, G. (2000). "Effect of substrate and cellulase concentration on simultaneous saccharification and 
fermentation of steam-pretreated softwood for ethanol production," Biotechnol. Bioeng. 68(2), 204-210. DOI: 10.1002/(SICI)1097-0290(20000420)68:2<204::AIDBIT9>3.0.CO;2-4

Talebnia, F., Karakashev, D., and Angelidaki, I. (2010). "Production of bioethanol from wheat straw: An overview on pretreatment, hydrolysis and fermentation," Bioresource Technol. 101(13), 4744-4753. DOI: 10.1016/j.biortech.2009.11.080

Wu, M. M., Chang, K., Gregg, D. J., Boussaid, A., Beatson, R. P., and Saddler, J. N. (1999). "Optimization of steam explosion to enhance hemicellulose recovery and enzymatic hydrolysis of cellulose in softwoods," Appl. Biochem. Biotech. 77(1-3), 47-53.

Yan, L., Zhang, L., and Yang, B. (2014). "Enhancement of total sugar and lignin yields through dissolution of poplar wood by hot water and dilute acid flowthrough pretreatment," Biotech. Biofuels 7(76). DOI: 10.1186/1754-6834-7-76

Yu, Z., Jameel, H., Chang, H., and Park, S. (2011). "The effect of delignification of forest biomass on enzymatic hydrolysis," Bioresource Technol. 102(19), 9083-9089. DOI: 10.1016/j.biortech.2011.07.001

Wood, T. M., and Bhat, K. M. (1988). "Methods for measuring cellulase activities," Methods Enzymol. 160(part A), 87-112.

Zhao, Y., Wang, Y., Zhu, J., Ragauskas, A., and Deng, Y. (2008). "Enhanced enzymatic hydrolysis of spruce by alkaline pretreatment at low temperature," Biotechnol. Bioeng. 99(6), 1320-1328. DOI: 10.1002/bit.21712

Article submitted: August 12, 2017; Peer review completed: October 1, 2017; Revised version received: December 23, 2017; Further revised version received and accepted: February 4, 2019; Published: March 12, 2019.

DOI: $10.15376 /$ biores.14.2.3567-3577 